Revista de Estudios Histórico-Jurídicos

[Sección Historia del Derecho Europeo]

XXXII (Valparaíso, Chile, 2010)

[pp. 309 - 322]

\title{
CAsos CÉlEBres de ALLANAMIENTO DOMICILIARIO EN LA ESPAÑA DEL SIGLO XVIII
}

\author{
[Renowned Cases of Official Entry and Search of Private Domiciles in the \\ Spain of the XVIII Century]
}

\author{
Silvia Pascual López*
}

\begin{abstract}
RESUMEN
Durante el siglo XVIII, el monarca "protege" personas y domicilios, como representante de todas las fuerzas sociales. La simple invocación a la persona del rey es suficiente para que magistrados y agentes entren en las moradas de los particulares con el fin de capturar o detener al delincuente que se halle en su interior. En esta época, ni siquiera el derecho de propiedad representa una protección suficiente frente a la voluntad del rey, quien puede, llegado el momento, expropiar sus posesiones a nobles y burgueses y, por supuesto, aprehenderlos dentro de sus hogares, sin mayores dificultades. España, aislada culturalmente del movimiento ideológico liberal que impregna a Europa y, por extensión, a las colonias americanas que van a independizarse de la metrópoli, no se incorporará a los derechos fundamentales constitucionalizados hasta principios del siglo XIX, tras dejar en el camino de la Historia allanamientos domiciliarios espectaculares de los que dan noticia el fenómeno marginal del bandolerismo, la expulsión de los jesuitas, y la peripecia personal y política de Jovellanos.

Palabra Clave: Inviolabilidad del hogar - Allanamiento del domicilio privado.
\end{abstract}

\section{AbSTRACT}

During the $18^{\text {th }}$ Century, the king 'protects' people and domiciles, as representative of all the social forces. Judges and agents simply need to invoke the King to enter into private domiciles in order to arrest or detain any felon that might be inside. At that time, not even the right of property stands as sufficient protection against the King's will who, at any given time, can expropriate possessions from noblemen and bourgeoisies and, of course, arrest them in their homes without great difficulty. Spain, culturally isolated from the liberal ideological movement that impregnates Europe and, by extension, to the American colonies that are to become independent from the metropolis, will not ascribe to the fundamental constitutional rights until the beginning of the $19^{\text {th }}$ Century, leaving behind in the path of History spectacular domicile official entries and searches, accounted for by the marginal phenomena of banditry, the expulsion of the Jesuits, and the personal and political vicissitudes of the Jovellanos.

KEYWORDS: Inviolability of the domicile - Official entry and search of private domicile.

* Doctora en Derecho por la Universidad de Deusto, Bilbao, Vizcaya, España. Dirección postal: Avda. Zumalacarregui No 101, 5 A, 48007 Bilbao, Vizcaya, España. Dirección electrónica: sil44ia@yahoo.es 


\section{INTRODUCCIÓN}

1. Una revolución ideológica, o cambio profundo en la mentalidad de la sociedad, como fue la Ilustración, resultó ser el factor determinante de la crisis del sistema económico, político y social imperante en el Antiguo Régimen.

Los principios de justicia, libertad e igualdad entre todos los individuos, difundidos por los ilustrados, constituyen grandes ideales utilizados por la burguesía en su lucha contra el absolutismo aún vigente.

Máximas del pensamiento ilustrado como ésta: "la política es el arte de hacer felices a los pueblos y para alcanzar dicha felicidad es obligado garantizar a los ciudadanos el disfrute de sus derechos", son fuente de inspiración de la Declaración de los Derechos del Hombre y del Ciudadano de 26 de agosto de 1789. Su contenido afirma la existencia de unos derechos naturales, fundamentales e imprescindibles: libertad, igualdad, propiedad, seguridad y resistencia a la opresión, que marcan el rumbo hacia la igualdad de todos los hombres ante la ley ${ }^{1}$.

La experiencia inglesa del Habeas Corpus Act de 1679, que proclama que ningún ciudadano puede ser detenido sin orden expresa y escrita, debiendo ser conducido en un plazo máximo de tres días ante un Tribunal, se prolonga en el tiempo en el contenido del artículo 7 de la Declaración de los Derechos del Hombre y del Ciudadano de 1789.

Aunque dicha Declaración no reconoce ni garantiza expresamente la protección domiciliaria, ésta puede entenderse implícita en la garantía de la libertad y seguridad personal, en el contexto del citado artículo 7: "Ningún hombre puede ser acusado, arrestado ni detenido más que en los casos determinados por la ley, y según las formas prescritas por ella. Los que soliciten, expidan, ejecuten o hagan ejecutar órdenes arbitrarias deberán ser castigados; pero todo ciudadano llamado o requerido en virtud de una ley debe obedecer al instante: de no hacerlo asi se hace culpable de resistencia”.

2. En España, los ilustrados profundizan en los problemas del país y se comprometen a aportar soluciones, apoyándose en una acción política fundamentada en la unificación y centralización del poder cuyos contenidos son: $i$ ) la abolición

\footnotetext{
${ }^{1}$ La expresión clásica "derecho natural" fue sustituida por la de "derechos del hombre" o "derechos fundamentales" a partir de la segunda mitad del S. XVIII, al fijarse por escrito en grandes textos y declaraciones de derechos. De hecho, la expresión "droits fondamentaux" aparece en Francia hacia 1770, en el interior del movimiento político y cultural que desembocó en la Declaración de los derechos del hombre y del ciudadano de 1789; al respecto, véase: Pérez LuÑo, Antonio Enrique, Derechos Humanos, Estado de Derecho y Constitución (Madrid, Tecnos, 1995), p. 30. Será preciso llegar a ese momento para que la inviolabilidad domiciliaria se convierta en uno de los derechos individuales mejor caracterizado, reconocido y consagrado en los documentos constitucionales. Véase: LuCAS Verdú, Pablo, Proclamación, formulación y significado de la Declaración de Derechos del Hombre y el Ciudadano de 1789, en LeTAMENDia Belzunde, F. - García Herrera, M. A. (editores), Derechos Humanos y Revolución Francesa (Bilbao, Universidad del País Vasco 1991), pp. 63-90; y ARTOLA, Miguel, Consideraciones en torno a la Revolución Francesa, en DE Diego, E. y otros (editores), Repercusiones de la Revolución Francesa en España (Madrid, Universidad Complutense de Madrid, 1990), pp. 19-30.
} 
de los regímenes específicos; ii) la creación de un modelo único de administración para todos los territorios de la Corona (excepto Navarra y las provincias vascongadas); y iii) la centralización del poder político ${ }^{2}$.

Esta última consideración sirve de punto de conexión con la materia objeto de nuestro estudio porque la garantía suprema de las personas y del domicilio queda en manos del rey.

El domicilio se allana en su nombre con una simple invocación a la autoridad regia. Cuando se grita "ffavor al rey!", se abren las puertas de las casas en las que penetran los magistrados y sus agentes para detener al presunto delincuente que se esconde en ellas. Es fácil comprender que en situaciones de esta naturaleza se dieran abusos.

Ni siquiera el derecho de propiedad constituye amparo eficaz frente a la disposición del soberano, quien puede, llegado el caso, desterrar a nobles y burgueses, desposeyéndolos de sus propiedades y, por supuesto, capturarles en el interior de sus moradas sin grandes resistencias.

3. No obstante, un auto del Consejo de Castilla de 9 de febrero de 1704 prescribe como formalidad garantista que: "Ningun Ministro inferior pueda por si allanar casa alguna no llevando auto de Juez, que expresamente lo mande"3.

Sin embargo, se admite el allanamiento en las siguientes situaciones sociales: indagación y prendimiento de manceba pública que habite con clérigo, reconocimiento y aprehensión real en casas particulares donde se juegue, y búsqueda del cuerpo del delito en caso de contrabando.

Por su parte, la Instrucción dirigida a Corregidores, Alcaldes Mayores y demás encargados del Gobierno de los pueblos, hecha pública por Real Cédula de 15 de mayo de 1788, en su número XX ordena a sus destinatarios que se "abstengan de tomar conocimiento de oficio en asuntos de disensiones domésticas interiores de padres e hijos, marido y muger, o de amos y criados, quando no haya quexa o grave escándalo, para no turbar el interior de las casas y familias, pues antes bien deben contribuir en quanto esté de su parte a la quietud y sosiego de ellas" ${ }^{4}$.

En este contexto se inscriben tres acontecimientos históricos de especial relevancia en relación con el domicilio como son el bandolerismo, la expulsión de los jesuitas, y la peripecia personal y política de Gaspar Melchor de Jovellanos.

${ }^{2}$ Cfr. Reguera Rodríguez, Antonio, Territorio ordenado, territorio dominado. Espacios, políticas y conflictos en la España de la Ilustración (León, Universidad de León, 1993), pp. $15-38$.

${ }^{3}$ Nueva Recopilación. Autos Acordados (edición facsimilar, Valladolid, Lex Nova, 1982), V, p. 28.

${ }^{4}$ En Figueroa Navarro, Ma Carmen, Aspectos de la protección del domicilio en el Derecho español (Madrid, Edisofer, 1998), p. 33. 


\section{LA LUCHA CONTRA EL BANDOLERISMO}

Respecto del primero, cuya mayor intensidad hay que situarla en el siglo XVIII y principios del XIX, el allanamiento domiciliario se produce por vía de delito.

Sus protagonistas, los bandoleros, "hijos de la miseria", por encontrarse inmersos en una sociedad que no tiene sitio, trabajo y comida para ellos ${ }^{5}$; se ven obligados a lanzarse a la ilegalidad, víctimas de una marginación derivada, en buena medida, de un cambio profundo en las estructuras económicas y sociales ${ }^{6}$.

$\mathrm{Su}$ actividad genera numerosos delitos contra la propiedad: robos en domicilios y escalanamientos de casas, que tratan de ser erradicados por una legislación que incrementa su severidad ante la proliferación masiva de tales infracciones ${ }^{7}$. Así, Felipe $\mathrm{V}$ persigue firme y obsesivamente los hurtos cometidos en la Corte, agravando las penas de las normas anteriores. El monarca se queja de la ineficacia y benignidad de las leyes vigentes e impone, mediante Pragmática sanción de 23 de febrero de 1734, la pena de muerte para todo individuo mayor de 17 años y sus cómplices, a quienes se pruebe haber entrado en la casa de una persona a robar, con o sin armas: "[...] Por quanto reconociendo, con lastimosa experiencia, la reiteración con que se comenten en la mi Corte, y Caminos immediatos, y publicos de ella, los delitos de Hurtos, y Violencias; enterado de que igual desenfreno, puede motivarse de la benignidad con que se ha practicado lo dispuesto por algunas Leyes del Reyno, sin embargo de lo prevenido por otras anteriores, que condignamente imponen la mayor pena para su castigo, y escarmiento; $y$ atendiendo a que mi Corte, como Fuente de Justicia, debe ser segura a todos los que vivieren, y residan en ella, he resuelto establecer nueva Ley, y Pragmatica Sancion, en esta forma. Que a qualquiera Persona, que teniendo diez y siete años cumplidos, dentro de mi Corte, y en las cinco leguas de su Rastro, y Distrito, le fuere probado aver robado a otro, ya sea entrando en las casas, o acometiendole en las calles, o caminos, ya con armas, o sin ellas, solo, o acompañado, y aunque no se siga herida, o muerte en la execucion del delito, se le deba imponer pena capital, assi por la Sala de Alcaldes de mi Casa, y Corte, como por los Jueces Ordinarios, y sin arbitrio para templar, ni commutar esta pena en alguna otra mas suave, y benigna. Que si el Reo de semejante delito, no tuviere la edad de diez y siete años cumplidos, y excediere de los quince, se le condene en la pena de doscientos azotes, y diez años de Galeras, y a que passados, no salga de ellas sin mi expresso consentimiento. Que si (lo que no es creíble) fuere probado a qualquiera Persona Noble aver cometido igual delito, no se le exceptue de la expressada pena capital, sino que se mande executar la de Garrote, irremissiblemente.

${ }^{5}$ Domínguez Ortiz, Antonio, La Sociedad española en el siglo XVIII (Madrid, Consejo Superior de Investigaciones Científicas, 1955), I, pp. 255-256.

${ }^{6}$ Se evidencia, en este momento, el axioma de la picaresca que reza "pobreza y picardía salieron de la misma cantera"; véase: SAlillas, Rafael, El delincuente español. Hampa (Antropología picaresca) (Madrid, Librería de Victoriano Suárez, 1898), p. 40.

${ }^{7}$ El cronista del siglo XVII, Barrionuevo, Jerónimo de, Avisos (1654-1658) (Madrid, Imprenta y Fundición de M. Tello, 1892), I, p. 119, relata cómo a 1 de noviembre de 1654: "Cada noche hay mil robos y escalamientos de casas, y andan los ladrones en cuadrillas de 10 en 10 y de 20 en 20 [...]. Con que la justicia de noche, en viendo de 3 á 4 de camada, luego los enjaulan; con que no caben en las cárceles de pie, sin distinción de personas, que la necesidad no halla otro oficio más á mano". 
Que todas las Personas que dieren auxilio cooperativo a tan grave, y escandaloso delito, sean condenados en la misma pena ordinaria de muerte, como complices, y perpetradores de su enormidad; y los que receptaren, o encubrieren maliciosamente algunos bienes de los robados, incurran en la pena de doscientos azotes, y diez años de Galeras, y en esta misma pena de Galeras, y azotes incurran aquellos, que acometiendo para executar el Hurto, no lograron el intento, ni la perfecta consumacion del delito, por algun accidente, o acaso, y si fueren Personas Nobles las que incurrieren en los dos ultimos expressados delitos, seran condenados en diez años de Presidio cerrado en el Africa, de que tampoco podrán salir sin mi expresso consentimiento [...]" .

Hacia 1780 se produce una intensificación notable de este fenómeno sociocriminal y, en consecuencia, la sociedad experimenta una mayor sensibilidad hacia los quebrantamientos de domicilios, por lo que demanda un aparato policial que vigile a quienes por su falta de medios sean proclives a delinquir.

Carlos III, para mayor seguridad pública y mejor administración de justicia, ordena a sus capitanes generales, el 25 de septiembre de 1781, que destinen las tropas bajo su mando a la persecución de bandidos, ofreciendo ascensos a los oficiales y a la tropa, así como parte del botín que confiscaren?.

En 1783 este planteamiento represivo-militar se incrementa al organizar y aumentar el número de efectivos "a fin de que su castigo contenga la osadía de los demás bandidos". Disponemos, en efecto, del siguiente documento conservado eb Novís. Recop. XII,17,2: “D. Carlos III. por Real órden de 24, y céd. del Consejo de 27 de Mayo de 1783: Persecucion de malhechores, breve determinacion de sus causas, y execucion de las penas que merezcan. Mando, que con las noticias que tengan las Justicias de las provincias, relativas al tránsito de los malhechores, acudan al Capitan General respectivo, pidiendo las partidas de tropas que necesiten; y que quando la urgencia no diese lugar, recurran á la tropa mas inmediata, para que las auxîlie. como lo executará puntualmente, y lo mismo practicarán las milicias, cuyos Coroneles tienen órden para hacerlo así. Las Chancillerías, Audiencias, Corregidores y Justicias del reyno por su parte no omitan diligencia para la prision de los delinqüentes; y verificada ésta, determinen prontamente sus causas, y hagan executar sin dilacion las penas que merezcan, á fin de que su castigo contenga la osadia con que los malhechores se han abandonado á toda clase de desórdenes y delitos, y se consiga restablecer la quietud y seguridad de mis vasallos" 10 .

$\mathrm{Al}$ año siguiente, Carlos III, en un nuevo intento de poner fin a la situación, dispone que las ejecuciones de penas de muerte contra bandoleros se lleven a cabo en los mismos pueblos en que hubieren delinquido, o en los inmediatos a los parajes despoblados que sean centro de operaciones. En el verano de ese mismo año 1784 se intensifica la captura militar de los bandidos, para que, acosados por

${ }^{8}$ Coronas González, Santos, El Libro de las Leyes del Siglo XVIII (Madrid, Boletín Oficial del Estado - Centro de Estudios Constitucionales, 1996), I, pp. 294-295.

${ }^{9}$ Tomás y Valiente, Francisco, El Derecho penal de la Monarquía absoluta (siglos XVI-XVII y XVIII) (2a edición, Madrid, Tecnos, 1992), pp. 268-269.

${ }^{10}$ En Martínez Alcubilla, Marcelo (editor), Códigos antiguos de España: Colección completa de todos los Códigos de España desde el Fuero Juzgo hasta la Novísima Recopilación (Madrid, Administración Arco de Santa María, 1885), II, p. 1882. 
todas partes, los malhechores se vean obligados a buscar otro medio honesto de vivir. La ley se encuentra en Novís. Recop. XII,17,4: “D. Carlos III. por Real órden de 18 y céd. de 24 de Junio de 1784. Observancia de los capitulos de la ley precedente para librar de insultos los caminos y pueblos. [...] quando por delitos de salteamientos, robos, homicidios causados en ellos ó en el contrabando se hubieren de imponer penas capitales, se executen estas en los pueblos en que se hubieren cometido los delitos, ó en los inmediatos á los parages despoblados en que tambien se hubieren cometido [...]"11.

La lucha entre tropas reales y bandoleros continúa hasta que el aumento del poder real y las represiones, cada vez más duras y continuas, contribuyan a la extinción del bandidaje. En cualquier caso, el factor más decisivo en su desaparición es el desarrollo económico que posibilita un cambio de estructuras sociales y un mejor nivel de vida. En realidad, los castigos, aun siendo eficaces, no han sido absolutamente determinantes para acabar con este tipo de delincuencia, pues incluso la propia población afectada, horrorizada por la dureza de las penas, desiste, en muchas ocasiones, de presentar denuncias ${ }^{12}$.

\section{LA EXPULSIÓN DE LOS JESUITAS}

Por lo que a la expulsión de los jesuitas se refiere, hay datos, procedentes de los investigadores del siglo XVIII, que presentan el tema con más pasión que rigor intelectual, básicamente a partir de reseñas de los propios religiosos afectados en las que el quebrantamiento domiciliario se describe con todo lujo de detalles ${ }^{13}$.

Por influencia de personajes ilustrados como Pedro Rodrigo de Campomanes, se deslizan sospechas en torno a la Compañía de Jesús como responsable más o menos directo de los motines y reivindicaciones que alteran la paz pública durante el reinado de Carlos III.

La aparente calma y complicidad entre Carlos III y su pueblo se rompe a principios de 1766, porque se encuentra soterrado un descontento general dominado por una lenta evolución en la concepción de la monarquía y la visión secularista del mundo y de la sociedad, que deja atrás viejas creencias sobre el carácter semidivino de los reyes. $\mathrm{Al}$ mismo tiempo, existen fuertes reticencias hacia la corte de ministros y favoritos extranjeros traídos de Nápoles por Carlos III y, en especial, hacia el marqués de Squillace, al que se le hace responsable de obras y reformas que no gozan del beneplácito de la masa de la nación. Entre estas últimas destacan la Ordenanza de 10 de marzo de 1766, en contra del traje popular compuesto por grandes sombreros y amplias capas. En su lugar, se impone vestir con capas cortas y sombrero de tres picos que permitan la identificación del rostro.

Sin embargo, es el encarecimiento de productos de primera necesidad, que por efecto de malas cosechas se elevan en la primavera de 1766, el suceso que más

\footnotetext{
${ }^{11}$ Novísima Recopilación, cit. (n. 3), V, p. 373.

${ }^{12}$ Martínez Ruiz, Enrique, La Seguridad pública en el Madrid de la Ilustración (Madrid, Ministerio del Interior, 1988), p. 23.

${ }^{13}$ Egido, Teófanes, La expulsión de los jesuitas de España, en García Villoslada, R. (director), Historia de la Iglesia en España, IV: La Iglesia en la España de los siglos XVII y XVIII (Madrid, Editorial Católica, 1979), p. 746.
} 
preocupa a las clases populares por la angustia y hambre física que padecen por muchas de ellas. La combinación de malas cosechas con una liberalización de los precios provoca una general escasez y carestía en la España de este tiempo, que aumenta la tensión en las calles del reino, manifestada en múltiples incidentes, como el destrozo de farolas, según parece, bautizadas con el nombre de Squillace y el saqueo de la morada de este último en Madrid, el Domingo de Ramos (23 de marzo); el asalto y quebrantamiento de la casa del intendente y de grandes comerciantes en Zaragoza ( 6 de abril); o el apedreamiento y violación de la residencia del corregidor en la población murciana de Lorca $(25 \text { de abril })^{14}$.

Una profunda preocupación en el ánimo del rey y su gobierno induce al monarca a emprender una "pesquisa reservada" para averiguar las causas y descubrir a los promotores de las algaradas. En abril de 1766 se encomienda la tarea al conde de Aranda que destaca, con este fin, dentro del Consejo de Castilla, un órgano especial, con el nombre de Consejo extraordinario ${ }^{15}$.

A partir de este momento, se dinamiza un largo y complicado proceso, cuyos principales artífices son el fiscal del Consejo, Pedro Rodríguez Campomanes, y el secretario de Estado y ministro de Gracia y Justicia, Manuel Roda, que concluirá con la expulsión de España, de los jesuitas.

La reunión del Consejo (29 de enero de 1767) ratifica la propuesta final incluida en el dictamen de Compomanes, a favor de la expulsión de los jesuitas y la ocupación de todos sus bienes, en último término examinada y aprobada por una Junta designada por el soberano, compuesta por dos consejeros de Castilla (duque de Alba y Jaime Masones de Lima), cuatro ministros (Grimaldi, Múzquiz, Muriain y Manuel Roda) y el confesor regio, Joaquín Eleta ${ }^{16}$.

El decisivo dictamen de Campomanes incorpora a lo descubierto por la pesquisa la existencia de un arsenal jesuítico, acumulado durante dos siglos. Se acusa a la Compañía de ser enemigo colectivo del gobierno de Carlos III y un peligro para la institución monárquica, en mérito de sus teorías sobre el probabilismo y el tiranicidio ${ }^{17}$, su relajada moral, su afán de poder y riquezas, sus posesiones en

${ }^{14}$ Véase: Domínguez Ortiz, Antonio, Carlos III y la España de la Ilustración (Madrid, Alianza Editorial, 1988), pp. 63-64; VILAR, Pierre, Hidalgos, amotinados y guerrilleros. Pueblo y poderes en la Historia de España (Barcelona, Editorial Crítica, 1982), pp. 104-105 y 119140; Eguia Ruiz, Constancio, El P. Isidro López y el Motín de Esquilache (Madrid, Razón y Fe, 1935), pp. 79-87.

${ }^{15}$ El Consejo extraordinario era una sala especial separada del Consejo pleno de Castilla, constituida por el conde de Aranda y un grupo reducido de anti jesuitas. Su misión era llevar a cabo una "pesquisa reservada" con el fin de averiguar los motivos y los autores de las grandes revueltas sociales originadas en Madrid. Sobre esto, véase: EGIDO, Teófanes - PINEdo, Isidoro, Las causas "gravísimas" y secretas de la expulsión de los Jesuitas por Carlos III (Madrid, Fundación Universitaria Española, 1994), pp. 26-56.

${ }^{16}$ Rivera VÁzquez, Evaristo, Galicia y los Jesuitas (La Coruña, Galicia Editorial, 1989), pp. 628-629; y VV. AA., La Compañia de Jesús en Bizkaia (Vitoria, Diputación Foral de Bizkaia, 1991), p. 96.

${ }^{17}$ Los jesuitas, con restricciones y variación externa de palabras, han procurado sostener en sus escritos, predicaciones y dictámenes, las opiniones reprobadas calificándolas de 'probables', aun cuando en la apariencia las impugnen, siendo máxima de su escuela que todo lo probable, que tiene autor a su favor, puede seguirse y aconsejarse. De ahi ha venido la secta o escuela que llaman 
Filipinas y América, sin que en todo el escrito pueda encontrarse algo positivo a su favor ${ }^{18}$.

Concluidas las pesquisas y a la vista de los resultados, Carlos III firma el 20 de febrero de 1767, en el Palacio de El Pardo, el Real Decreto de expulsión de los jesuitas de España y de sus posesiones ultramarinas. La "Exposición de Motivos" justifica así la decisión: "Habiéndome conformado con el parecer de los de mi Consejo Real [...], estimulado de gravísimas causas, relativas a la obligación en que me hallo constituido de mantener en subordinación, tranquilidad y justicia mis pueblos, y otras urgentes, justas y necesarias, que reservo en mi real ánimo, usando de la suprema autoridad económica que el Todopoderoso ha depositado en mis manos para la protección de mis vasallos y respeto de mi Corona; he venido en mandar extrañar de todos mis dominios e Indias, islas Filipinas y demás adyacentes, a los regulares de la Compañia, asi sacerdotes como coadjutores o legos, que hayan hecho la primera profesión, y a los novicios que quisieren seguirles, y que ocupen todas las temporalidades de la Compañia en mis dominios [...]"19.

A resultas de la decisión, y con el mayor de los sigilos, el día 31 de marzo en Madrid, y el 2 y 3 de abril en provincias, todas las casas, colegios y edificios de los jesuitas son clausurados, cercados, incomunicados y violados ${ }^{20}$.

Como testimonio del mayor quebrantamiento de domicilios realizados en una sola noche, consignamos el que se lleva a cabo en el Colegio de San Matías de Oviedo, la noche del jueves 2 al viernes 3 de abril de 1767: “[...] Inmediatamente que se franqueron las puertas, entro con apresurado tropel la gente armada que estaba prevenida, para ocupar los claustros, transitos, dormitorios, puertas de aposentos, piezas comunes y particulares, sin reservar en algunas partes aquellas que el consentimiento universal ha declarado privadas, porque asi lo requieren la modestia, la necesidad $y$ decencia.l Todos estos sitios se vieron de repente ocupados de uno o mas centinelas con bayonetas caladas. Lo mismo se practico generalmente con las puertas interiores de la iglesia y sacristia; pero en el Colegio de Oviedo se cometio en este particular un exceso tanto mas reparable, cuanto su ejecución fue por orden de un Ministro tan sabio, tan cristiano y tan moderado como es el que actualmente preside y rige aquella Real Audencia [Don Antonio de Veyan y Monteagudo]. Luego que entro en dicho Colegio con un peloton de soldados, ministros de justicia y criados suyos, se fue derecho al aposento del Padre Rector, sin que en su presencia apareciese persona alguna

de 'probabilistas', de cuya lubricidad de opinar pretenden eruditisimos varones haber recibido la Iglesia no menores males que de la herejía. [...] convencen la calumnia de los escritores jesuitas, sino que demuestra haber sido el padre Juan de Mariana, jesuita, por otro lado docto, el primero que propagó en España la doctrina regicida y tiranicida, dando a los pueblos ánimo para atropellar a las potestades superiores. Véase: Rodríguez de Campomanes, Pedro, Dictamen fiscal de expulsión de los Jesuitas de España (1766-1767) (Edición, Introducción y Notas de Jorge Cejudo y Teófanes Egido, Madrid, Fundación Universitaria Española, 1977), pp. 142 y 148.

${ }^{18}$ BATLlorí, Miguel, La expulsión de los jesuitas y el jurisdiccionalismo antirromano: raíces napolitanas y austracistas, Carlos III y la Ilustración (Barcelona-Madrid, Lunwerg Ediciones, 1989), I, p. 244.

${ }^{19}$ Véase: García-Villoslada, Ricardo, Manual de Historia de la Compañía de Jesús (2a edición, Madrid, Compañía Bibliográfica Española, 1954), pp. 544-546.

${ }^{20}$ Egído, Teófanes, La expulsión, cit. (n. 13), IV, pp. 750-759. 
eclesiastica; y llevandole consigo a la iglesia, mando abrir sus puertas exteriores para introducir en ella el cuerpo de guardia, compuesto de 6 ú 8 soldados que tenia prevenidos, los que entraron en el templo con bayonetas caladas, y penetrando por medio de el hasta la sacristia, dejaron sus puertas cerradas, como las exteriores y las interiores de la iglesia. Causo desde luego esta inesperada accion la disonancia y el dolor que se dejan considerar, viendo tan atropellada la casa de Dios con notoria violacion de su sagrada inmunidad; pero se hizo despues mucho mas extrañable esta violencia, cuando se leyo lo que cristianamente prescribe el capitulo VIII de la Instruccion, sobre el respeto y la decencia con que se ha de tratar todo lo que perteneciese a la iglesia y sacristia, suponiendose que en estas sagradas oficinas nada se podia practicar sin intervencion de Provisor, Vicario Eclesiastico o Cura de pueblo, a falta de Juez eclesiastico legitimo. $N i$ deja de ser digno de reparo que el Regente anduviese tan apresurado en aquella diligencia, como que fue la primera que hizo despues que entro en el Colegio, siendo asi que era la octava en el orden de las que se le encomendaban, no descubriendose razon alguna para esta menos considerada apresuracion; puesto que los soldados que esperaban a la puerta de la iglesia, igualmente podian entrar por la porteria comun del Colegio que tenia el Ministro a su disposición./ Salida de los PP. de la Compañía del Muelle de Gijón con destino al destierro./ Embarcaronse en fin los jesuitas de Santander, para reunirse con todos los demas en el puerto del Ferrol; y se hizo muy digno de reparo, que asi a estos como a los tres convoyes que zarparon de Santander, Bilbao y Gijon en Asturias, se les obligo a salir del puerto con viento contrario, a pesar de la representacion del piloto, el cual arreciandose cada dia mas el mar, y amenazando con los funestos efectos que son tan frecuentes en aquella brava costa de Cantabria, despues de ocasionarles una tarda y penosisima navegacion, los puso repetidas veces a dos dedos de un miserable naufragio. Librolos de el la amorosa providencia del Señor; y habiendo aportado todas las embarcaciones al termino de la general reunion, se dispuso al embarco general para los Estados del Papa, distribuyendolo en dos convoyes: escoltado y mandado el uno por el navio de guerra San Jenaro, y el otro por el navio, tambien de guerra, San Juan Nepomuceno" 21 .

\section{LA DETENCIÓN DE JOVELlanos Y EL ALLANAMIENTO DE SU MORADA}

El caso Jovellanos comienza en 1767, precisamente el año de la expulsión de los jesuitas, cuando el ilustre e ilustrado polígrafo asturiano toma la decisión de abandonar su carrera eclesiástica e iniciar otra al servicio del Estado como alcalde de La Cuadra, en Sevilla ${ }^{22}$.

A partir de este momento, comienza una azarosa vida que le reserva los más altos cargos en política, la más denigrante de las persecuciones, y el encarcelamiento. El propio Jovellanos, treinta y cuatro años después, dará testimonio personal del allanamiento de su propia morada.

\footnotetext{
${ }^{21}$ García SÁnchez, Justo, Los Jesuitas en Asturias. Documentos (Oviedo, Universidad de Oviedo, 1992), pp. 498-499.

${ }^{22}$ El Alcalde de la Sala del Crimen de la Audiencia de Sevilla era llamado así porque a la Sala Capitular de su Ayuntamiento se la conocía como la "Cuadra". Véase: ABELLÁn, José Luis, Gaspar Melchor de Jovellanos. Poesía. Teatro. Prosa (Madrid, Taurus, 1979), pp. 7-25.
} 
En la madrugada del 13 de marzo de 1801, como él mismo relata, es sorprendido en su cama por el regente de la Audiencia de Asturias que, en nombre del rey, le incomunica y se apodera de sus papeles. Antes del amanecer del día siguiente, la escolta de soldados que le vigila y el propio regente le conducen hasta León, donde permanece recluso en el Convento de Franciscanos Descalzos por espacio de diez días. En este período de tiempo no se le permite contacto alguno con el exterior.

De León es trasladado, por Burgos y Zamora, a Barcelona sin que le sea permitido hablar con nadie durante el camino y, una vez allí, en la ciudad condal, encerrado en el convento de La Merced, con el mismo rigor y privación de trato.

Finalmente, y como si ya no fuera digno de pisar la península, es embarcado y trasladado a Palma de Mallorca, presentado a su capitán general y condenado al confinamiento en la isla.

Apenas instalado en la Cartuja de Valldemosa, seriamente custodiado y con órdenes rigurosas de que se relacione solamente con monjes, Jovellanos escribe a Carlos IV una carta tan respetuosa como enérgica ( 24 de abril). En ella ruega con respeto, pero con firmeza, que se le haga saber la causa de tan duro e ignominioso tratamiento y que se oigan sus defensas, con arreglo a las leyes, ante cualquier tribunal públicamente reconocido.

Absolutamente convencido de su inocencia proclama con amargura: "[...] Pues iqué! allanar la casa de un hombre que está en plena posesión de su inocencia, escudriñar hasta sus últimos retretes, invadir y ocupar, sin distinción alguna, todos sus papeles; unos papeles en que debian estar consignados, no sólo sus intereses, sus derechos, sus escritos y el fruto de sus estudios y trabajos, sino también sus pensamientos, sus aficiones, sus flaquezas, las confianzas de sus amigos y parientes, y en una palabra, los más intimos secretos de su conciencia y de su vida, ¿no habrá sido lo mismo que invadir y violar el más sagrado de todos los depósitos? ¿No habrá sido profanar, atropellar y hollar con los pies la más preciosa de todas las propiedades, la más intima, la más religiosa, la más identificada con la vida y existencia del hombre?"23

Esta denuncia y otra formulada meses después (8 de octubre) en la que se solicita justicia " no sólo para mí, sino para mi nación, porque no hay un hombre de bien en ella a quien no interese mi desagravio. La opresión de mi inocencia amenaza la suya, y el atropellamiento de mi libertad pone en peligro y hace vacilante la de todos mis conciudadanos" ${ }^{24}$, no llegarán jamás a manos del monarca ${ }^{25}$.

\footnotetext{
${ }^{23}$ Caso González, José Miguel, Gaspar Melchor de Jovellanos. Memoria en defensa de la Junta Central (Oviedo, Junta General del Principado, 1992), II, p. 31.

${ }^{24}$ VArela, Javier, Jovellanos (Madrid, Alianza Editorial, 1988), p. 183.

${ }^{25}$ Jovellanos mandó la primera de sus cartas al marqués de Valdecarzana, primo suyo, hombre apocado y tímido, pero con gran influencia en la Corte. Al enterarse que éste no se atrevió a presentar o entregar dicho documento, escribió otro con copia del anterior y lo mandó a su casa, encomendando al capellán de ella, José Antonio Sampil, que lo llevare a la Corte y se asegurare de su entrega al rey. En su cometido fue detenido y encarcelado en la prisión denominada La Corona, destinada exclusivamente para clérigos. Para todo, véase: ARTOla, Miguel (editor), Biblioteca de autores españoles, desde la formación del lenguaje hasta nuestros dias. Obras publicadas e inéditas de Don Gaspar Melchor de Jovellanos (Madrid, Atlas, 1956), III, pp. liv-lv.
} 
Entre tanto, los amigos de Jovellanos trabajan afanosamente en la difusión por Madrid de ambos documentos, demostrativos de su inocencia, lo cual genera un ambiente de creciente simpatía hacia el desterrado perseguido que llega a oídos del rey y sus ministros ${ }^{26}$. Jovellanos es trasladado de Valldemosa al castillo de Bellver, a tres kilómetros de Palma ${ }^{27}$.

Ni la nueva prisión, ni sus medidas de seguridad, impiden al recluso remitir cartas fuera de la fortaleza y recibir las que le dirigen parientes y amigos.

En 1808, la abdicación de Carlos IV en Fernando VII trae consigo la orden de libertad para Jovellanos, firmada por el mismo ministro que siete años atrás diera la de recluirlo en la cárcel: "Excelentísimo señor: El Rey, nuestro señor, don Fernando VII se ha servido alzar a V.E. el arresto que sufre en ese castillo de Bellver, y S.M. permite a V.E. que pueda venir a la corte. Lo que de real orden lo comunico a V.E. para su inteligencia y satisfacción. Dios guarde a V.E. muchos años.- Aranjuez, 22 de marzo de 1808. El marqués Caballero. Señor don Gaspar Melchor de Jovellanos" 28 .

Jovellanos comunica la buena nueva a su amigo Juan Ezcoiquiz (14 de abril) a quien le hace saber que "logrado que haya la declaración de mi inocencia, solo pretenderé, en premio de mis servicios, que se me permita volver al rincón de donde me sacaron". Esto significa que solicita únicamente la restitución de las comisiones que le fueron encargadas antaño en Asturias: fomentar el comercio del carbón de piedra, restablecer y perfeccionar el Instituto Asturiano, y dirigir el camino de León y Asturias para hacer felices a sus dos grandes provincias ${ }^{29}$.

Obsesionado por la reintegración de su fama y buen nombre, que considera totalmente violados desde su injusta detención, destierro y prisión, escribe una nueva carta al rey Fernando VII (18 de abril) a quien agradece el beneficio de su libertad al mismo tiempo que le reclama un juicio público: " $Y$ si, como mi conciencia me asegura, resultare de este examen, no sólo mi inocencia, sino también el constante celo y desinterés con que serví a los augustos padre y abuelo de V.M. desde el año de 1767, ruego humildemente a V.M. se digne declarar uno y otro por su real decreto, mandando anular y suprimir los citados expedientes y las órdenes expedidas a consecuencia de ellos, la restitución de todos mis papeles, la indemnización de las personas que hubieren sufrido por mi causa, y lo demás que su suprema justicia estimare necesario para la completa reintegración de mi estado y buen nombre" 30 .

Una vez más, la petición no tendrá respuesta.

Jovellanos regresa a Barcelona el 20 de mayo de 1808 reincorporándose a la

${ }^{26}$ Véase: SÁnCHEZ, Miguel, Vida de Jovellanos (Madrid, Imprenta de Enrique de la Riva, 1881), pp. 27-38.

${ }^{27}$ Véase: Martínez, Elviro (editor), Gaspar Melchor de Jovellanos. Obras históricas. Sobre la Legislación y la Historia. Discurso sobre la Geografía y la Historia. Sobre los espectáculos y las diversiones públicas. Descripción del castillo de Bellver. Disciplina eclesiástica sobre sepulturas (México, Pórrua, 1984), pp. 86-147.

${ }^{28}$ Caso González, Gaspar Melchor de Jovellanos, cit. (n. 23), II, p. 27; y Fernández Álvarez, Manuel, Jovellanos (Madrid, España Mañana, 1988), p. 174.

${ }^{29}$ Gómez de la Serna, Gaspar, Jovellanos, el español perdido (Madrid, Organización Sala Editorial, 1975), II, pp. 177-178.

${ }^{30}$ Caso GonzÁlez, Gaspar Melchor de Jovellanos, cit. (n. 23), II, pp. 28-29. 
política activa en la Junta Central, órgano trascendental durante la guerra de la independencia.

En este tiempo, dividida la conciencia española entre los principios liberales e integristas, Jovellanos armoniza en una unidad superior las distintas tendencias -conservadoras y reformistas- que anidan en el espíritu de un sector constituyente. Desde un punto de vista político, esa armonía se proyecta en el espíritu de la Constitución gaditana, en ella las construcciones de la razón se conectan con las aportaciones de la Historia: “Por ventura no tiene España Constitución? Tiénela sin duda; ¿porque qué otra cosa es una Constitución que el conjunto de leyes fundamentales que fijan los derechos fundamentales del soberano y de los súbditos y los medios saludables de preservar unos y otros? ¿Y quién duda que España tiene estas leyes $y$ las conoce? ¿Hay algunas que el despotismo haya atacado y destruido? Restablézcanse. ¿Falta alguna medida saludable para asegurar la observancia de todas? Establézcase. Nuestra Constitución, entonces, estará hecha y merecerá ser enviada por todos los pueblos de la tierra que amen la justicia, el orden, el sosiego público y la verdadera libertad, que no puede existir sin ellos" 31.

El hecho de haber unido su nombre a la Junta Central le ocasiona en 1810, junto a sus compañeros, un vergonzoso registro ${ }^{32}$, posteriores persecuciones y detenciones al ser acusados de robo y fuga de grandes sumas de dinero.

[Recibido el 22 de diciembre de 2009 y aceptado el 31 de marzo de 2010].

\section{BiBLIOGRAFÍA}

AA. VV., La Compañia de Jesús en Bizkaia (Vitoria, Diputación Foral de Bizkaia, 1991).

Abellán, José Luis, Gaspar Melchor de Jovellanos. Poesía. Teatro. Prosa (Madrid, Taurus, 1979).

ARtola, Miguel (editor), Biblioteca de autores españoles, desde la formación del lenguaje hasta nuestros Días. Obras publicadas e inéditas de Don Gaspar Melchor de Jovellanos (Madrid, Atlas, 1956), III.

Artola, Miguel, Consideraciones en torno a la Revolución Francesa, Repercusiones de la Revolución Francesa en España (Madrid, Universidad Complutense de Madrid, 1990).

${ }^{31}$ En Sánchez Agesta, Luis, Curso de Derecho constitucional comparado (7a edición, Madrid, Universidad de Madrid, 1980), p. 426.

${ }^{32} \mathrm{~A}$ su regreso a Gijón, y después de soportar una tormenta de tres días en la que estuvieron a punto de naufragar, el velero "Covadonga" buscó refugio el día 6 de marzo de 1810 en la ría coruñesa de Muros. En los primeros días de su estancia en esta localidad gallega, Jovellanos y Camposagrado recibieron la incómoda visita de los comisionados de las Juntas de La Coruña y Santiago. Ambos debieron soportar la recogida de sus pasaportes e, incluso, que se pretendiese el registro de sus papeles. Peor suerte tuvieron algunos otros centrales que, además de sufrir en Cádiz la inspección de sus equipajes y de ser tratados como estafadores del Erario, fueron apresados temporalmente a su llegada a El Ferrol. Todo en CABEZAS, Juan Antonio, Jovellanos. El fracaso de la Ilustración (Madrid, Silex, 1985), pp. 207-209. 
Barrionuevo, Jerónimo de, Avisos (1654-1658) (Madrid, Imprenta y Fundición de M. Tello, 1892), I.

BATLLORÍ, Miguel, La expulsión de los jesuitas y el jurisdiccionalismo antirromano: raices napolitanas y austracistas, Carlos III y la Ilustración (Barcelona - Madrid, Lunwerg Ediciones, 1989), I.

Cabezas, Juan Antonio, Jovellanos. El fracaso de la Ilustración (Madrid, Silex, 1985).

CAso GonzÁlez, José Miguel, Gaspar Melchor de Jovellanos. Memoria en defensa de la Junta Central (Oviedo, Junta General del Principado, 1992), II.

Coronas GonzÁlez, Santos, El Libro de las Leyes del Siglo XVIII. Colección de impresos legales y otros papeles del Consejo de Castilla (1708-1781) (Madrid, Boletín Oficial del Estado - Centro de Estudios Constitucionales, 1996), I.

Domínguez Ortiz, Antonio, Carlos III y la España de la Ilustración (Madrid, Alianza Editorial, 1988).

Domínguez Ortiz, Antonio, La Sociedad Española en el Siglo XVIII (Madrid, Consejo Superior de Investigaciones Científicas, 1955), I.

EGIDO, Teófanes - Pinedo, Isidoro, Las Causas "gravísimas y secretas de la expulsión de los Jesuitas por Carlos III (Madrid, Fundación Universitaria Española, 1994).

Egido, Teófanes, La expulsión de los jesuitas de España, en GarCía Villoslada, R. (director), Historia de la Iglesia en España, IV: La Iglesia en la España de los siglos XVII y XVIII (Madrid, Editorial Católica, 1979).

Eguia Ruiz, Constancio, El P. Isidro López y el Motín de Esquilache (Madrid, Razón y Fe, 1935).

Novisima Recopilación de las Leyes de España (Madrid, Boletín Oficial del Estado, 1992), V.

Nueva Recopilación. Autos Acordados (Valladolid, Lex Nova, 1982), V.

Fernández Álvarez, Manuel, Jovellanos (Madrid, España Mañana, 1988).

Figueroa Navarro, $\mathrm{M}^{\mathrm{a}}$ Carmen, Aspectos de la protección del domicilio en el Derecho español (Madrid, Edisofer, 1998).

García Sánchez, Justo, Los Jesuitas en Asturias (Oviedo, Universidad de Oviedo, 1992).

García-Villoslada, Ricardo, Manual de Historia de la Compañia de Jesús (2a edición., Madrid, Compañía Bibliográfica Española, 1954).

Gómez de la Serna, Gaspar, Jovellanos, el español perdido (Madrid, Organización Sala Editorial, 1975), II.

LuCAS Verdú, Pablo, Proclamación, formulación y significado de la Declaración de Derechos del Hombre y el Ciudadano de 1789, en Letamendia Belzunde, F. - García Herrera, M. A. (editores), Derechos humanos y Revolución Francesa (Bilbao, Universidad del País Vasco 1991).

Martínez Alcubilla, Marcelo (ed.), Códigos Antiguos de España: Colección Completa de Todos los Códigos de España desde el Fuero Juzgo hasta la Novisima Recopilación, Administración Arco de Santa María (Madrid, 1885), II.

Martínez Ruiz, Enrique, La seguridad pública en el Madrid de la Ilustración (Madrid, Ministerio del Interior, 1988).

Martínez, Elviro (editor), Gaspar Melchor de Jovellanos. Obras Históricas. Sobre la Legislación y la Historia. Discurso sobre la Geografía y la Historia. Sobre los espectáculos y las diversiones públicas. Descripción del castillo de Bellver. Disciplina eclesiástica sobre sepulturas (México, Pórrua, 1984). 
Reguera Rodríguez, Antonio, Territorio ordenado, territorio dominado. Espacios, politicas y conflictos en la España de la Ilustración (León, Universidad de León, 1993).

Rivera Vázquez, Evaristo, Galicia y los Jesuitas (La Coruña, Galicia Editorial, 1989).

Rodríguez de Campomanes, Pedro, Dictamen fiscal de expulsión de los Jesuitas de España (1766-1767) (Edición, introducción y notas de Jorge Cejudo y Teófanes Egido, Madrid, Fundación Universitaria Española, 1977).

Salillas, Rafael, El Delincuente Español. Hampa (Antropología picaresca) (Madrid, Librería de Victoriano Suárez, 1898).

SÁnChez Agesta, Luis, Curso de Derecho constitucional comparado (7a edición, Madrid, Universidad de Madrid, 1980).

SáncheZ, Miguel, Vida de Jovellanos, Imprenta de Enrique de la Riva (Madrid, 1881).

Tomás y Valiente, Francisco, El Derecho penal de la Monarquía absoluta (siglos XVIXVII y XVIII) (2a edición, Madrid, Tecnos, 1992).

VARELA, Javier, Jovellanos (Madrid, Alianza Editorial, 1988).

VILAR, Pierre, Hidalgos, amotinados y guerrilleros. Pueblo y poderes en la Historia de España (Barcelona, Editorial Crítica, 1982). 